\title{
SENSORY EVALUATION AND ELECTRONIC TONGUE FOR SENSING GRAFTED AND NON-GRAFTED WATERMELON TASTE ATTRIBUTES
}

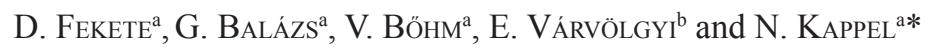 \\ ${ }^{a}$ Department of Vegetable and Mushroom Growing, Faculty of Horticultural Science, Szent István University, \\ H-1118 Budapest, Villányi út 29-43. Hungary \\ ${ }^{\mathrm{b}}$ Department of Physics and Control, Faculty of Food Science, Szent István University, \\ H-1118 Budapest, Somlói út 14-16. Hungary
}

(Received: 20 February 2018; accepted: 11 May 2018)

\begin{abstract}
The objective of our study was to analyse the results of two measuring methods (sensory evaluation and electronic tongue) and to find differences in taste between grafted and non-grafted watermelon fruit. The trained sensory panel evaluated in two years three differently treated watermelon fruit. The studied fruit samples were produced on the same growing-areas in both years but with different growing technologies. The experiment used the non-grafted/ self-rooted watermelon as control sample, while the other two treatments were grafting on two rootstock types: a Lagenaria and an interspecific squash hybrid rootstock. The electronic tongue measurement showed that it is the environment/growing technology that mainly determines the characteristics of the fruit quality, not grafting. The two measurement methods can complement each other in a detailed and practical way, as technology and growing area strongly influence the quality of watermelon fruit. The research also showed that it is possible to have similar watermelon fruit quality, independently from the used rootstock type.
\end{abstract}

Keywords: sensory evaluation, electronic tongue, watermelon, rootstock

The environment, production conditions, agricultural practices, consumer preferences highly influence the quality and nutritional value of food (KHAKIMOv et al., 2015).

The taste of food products is one of the most important quality measures. Sensory evaluation is time consuming, expensive, and even trained panelists could be influenced by several psychological factors. The concept of the electronic tongue is to measure a 'fingerprint' of the samples, allowing sensitive comparison, which makes the technique suitable for taste measurements. Therefore, determination of sensory attributes by instrumental measurements is a major trend nowadays.

Sensory profiling is a powerful tool for the food industry, as it provides important information for the development and marketing of new products, the reformulation of existing products, and the optimization of manufacturing processes (GERE et al., 2017). This methodology has always been performed with a group of trained assessors, because they consistently provide a quantitative description of the sensory characteristics of food products (Losó et al., 2012; GERE et al., 2014, 2015). Several literature sources concluded that electronic tongues are capable of predicting, for example Italian red wine taste attributes (BuRATTI et al., 2007), apple juice preference (Bleibaum et al., 2002), or to discriminate between mineral waters (SiPos et al., 2012). Moreover, electronic tongue has been moved further in trend of getting prediction models based on the results of consumers (BLEIBAUM et

* To whom correspondence should be addressed.

Phone: +36 14826225; e-mail: kappel.noemi@kertk.szie.hu 
al., 2002) and experts (SIPOs et al., 2013) for predicting different sensory attributes of different food products.

Our aim in the study was to develop and evaluate electronic tongue models as an approximating tool for predicting the taste of watermelon samples. In the same context, this research will lead to twofold solution of the dilemmas of sensory analysis process. Our goal was to compare and analyse the results of the two measuring methods and find the differences in taste between the grafted and non-grafted watermelons. The grafting of vegetables first was used to increase the endurance against the soil-born diseases, but later works were reported on vigorous root system, tolerance to environment stresses, increased fruit yield, etc. (DAvis et al., 2008). Nevertheless, regarding watermelon there are many conflicting reports on changes in fruit quality due to grafting (FALLiK \& ILIĆ, 2014).

\section{Materials and methods}

Watermelon was produced in three different Hungarian growing regions (Békés, JászNagykun-Szolnok and Fejér county) with three different technologies. In Békés county we used low plastic tunnel covering, irrigation system, and soil mulching. In the Jász-NagykunSzolnok region irrigation system and mulching were used. In Fejér county the growing technology was extensive, without irrigation system, only with soil mulching.

The experiment was carried out in 2013 and 2014. Non-grafted watermelons (in 2013 one triploid watermelon "RX 467" variety, in 2014 a well-known watermelon variety "Bonta") were used as control. The scion was grafted on two commercial watermelon rootstocks "FR STRONG" (Lagenaria siceraria (Mol.) Standl.) and "RS 841" (Cucurbita maxima Duchesne $\times$ Cucurbita moschata Duchesne interspecific squash hybrid).

The fully ripe fruit from the different regions were harvested and tasted separately. The fruit samples each year were harvested from the three threatments. The sensory evaluations were carried out on the next day of harvest. The preparation of the watermelon slices was conducted using standardized parameters each year (sample quantity, size, temperature, etc.) (ISO, 2005).

\subsection{Applied samples}

The sample codes were made of the nearest town or village name (C: Cece, J: Jászszentandrás, Ú: Újkígyós) and the treatment: self-rooted (S) or grafted on the two different types of rootstock (L: Lagenaria type, I: interspecific squash hybrid). Cece village (46 46 $46^{\prime} 09.22 \mathrm{~N}-$ $\left.18^{\circ} 37^{\prime} 46.96^{\prime \prime} \mathrm{E}\right)$ can be found in Fejér county, Jászszentandrás village (47³5’04.52” N $20^{\circ} 10^{\prime} 25.16^{\prime \prime}$ E) in Jász-Nagykun-Szolnok county and Újkígyós town (46³5'19.85" N $\left.21^{\circ} 01^{\prime} 30.18^{\prime \prime} \mathrm{E}\right)$ in Békés county.

\subsection{Trained panel sensory evaluation}

Both years, sensory evaluations were conducted at the qualified Sensory Evaluation Laboratory of Szent István University (ISO, 2007). Panellists went through a training that meets the requirements of the ISO (2012) standard. Tests were conducted using two replicates to ensure data reliability. The watermelon fruit was sliced into four equal parts (along the longitudinal axis), then the two ends of the quarter were removed. The remaining part was cut into similar slices. The samples were evaluated on a scale between 0 and 100 for each of the 
following 17 attributes (ISO, 1994): intensity of red colour, rind thickness, amount of seeds, venousness, crispness, mushiness, fibrosity, juiciness, global odor intensity, squash odour, global taste intensity, sweet taste, squash taste, sour taste, taste persistency, aftertaste, and off-flavour.

\subsection{Electronic tongue measurements}

Alpha Astree II electronic tongue (Alpha M.O.S., Toulouse, France) was used for the measurement of watermelon juices. It is composed of seven ISFET (ion sensitive field effect transistor) potentiometric chemical sensors and an $\mathrm{Ag} / \mathrm{AgCl} 3 \mathrm{M} \mathrm{KCl}$ reference electrode.

The sensors are characterized by cross-sensitivity and partial selectivity for the different flavour components.

From each treatment 3-4 watermelons were sliced. The fruit flesh was pressed, and then it was filtered through a paper filter. The filtered juice was filled into a falcon tube.

The watermelon samples were not diluted, they were measured five times. Measurements were performed at room temperature with the following conditions: $100 \mathrm{ml}$ sample volume, $120 \mathrm{~s}$ analysis time, $10 \mathrm{~s}$ cleaning time.

For the statistical evaluation, the sensor signals in equilibrium state were considered as variables. After the application of several pattern recognition algorithms, the data were evaluated with multivariate statistical methods.

The multivariate sensor data requires dimensional reduction, which was obtained with a non-supervized method (PCA-principal component analysis). The originally high amount of variables (seven sensors) was summarized into a new set of uncorrelated variables, known as principal components (RichARDS et al., 2002). Furthermore, linear discriminant analysis (LDA) was applied as a supervised method in order to evaluate the capability of discrimination of the current system maximizing the distances between classes by transformation of variables. Cross-validation was applied, 2/3 part of the data was used for calibration and the rest (1/3) of the data for validation (BERRUETA et al., 2007). All computations and chemometric analysis were carried out using the software R-studio 3.0.

\subsection{Data analysis}

Data of the sensory sessions did not follow normal distribution based on the results of Shapiro-Wilk and Kolmogorov-Smirnov tests; hence the nonparametric Mann-Whitney U-test was applied to test the differences between the two years (2013 and 2014). The significance level was $5 \%(\mathrm{P}<0.05)$.

Electronic tongue data was evaluated by principal component analysis (PCA), which is a multivariate explanatory method and is able to detect possible patterns present in the data set. Linear discriminant analysis (LDA) was applied to create classification of the two years. All computations were carried out using XL-STAT Sensory Solution (Pro module) created by Addinsoft. PCA was performed based on the work of SiPOs and co-workers (2013).

The performance monitoring of the trained panel was carried out according to the workflow of the PanelCheck software using one- and multi-way statistical methods: detecting the non-significant product effects (2-way ANOVA, significance levels were 95\% and 99\% $(\mathrm{P}<0.05, \mathrm{P}<0.01)$; identifying panelists who differ from the rest of the panel (Tucker-1 plot, Manhattan plot); analysing the discriminating ability of the panelists (F plots, MSE plots, p*MSE plots)) (Losó et al., 2012). 


\section{Results and discussion}

\subsection{Electronic tongue measurements}

In 2013's electronic tongue analysis, after outlier detection, PCA plot represented a good separation of the sample groups based on their origin (Fig. 1). The first two principal components contained more than $95 \%$ of the data variance. The samples were discriminated according to the regions by the first two principal components. The sample points of the regions Újkígyós and Jászszentandrás were well discriminated, however some points of region Újkígyós overlapped with the points of Cece region.

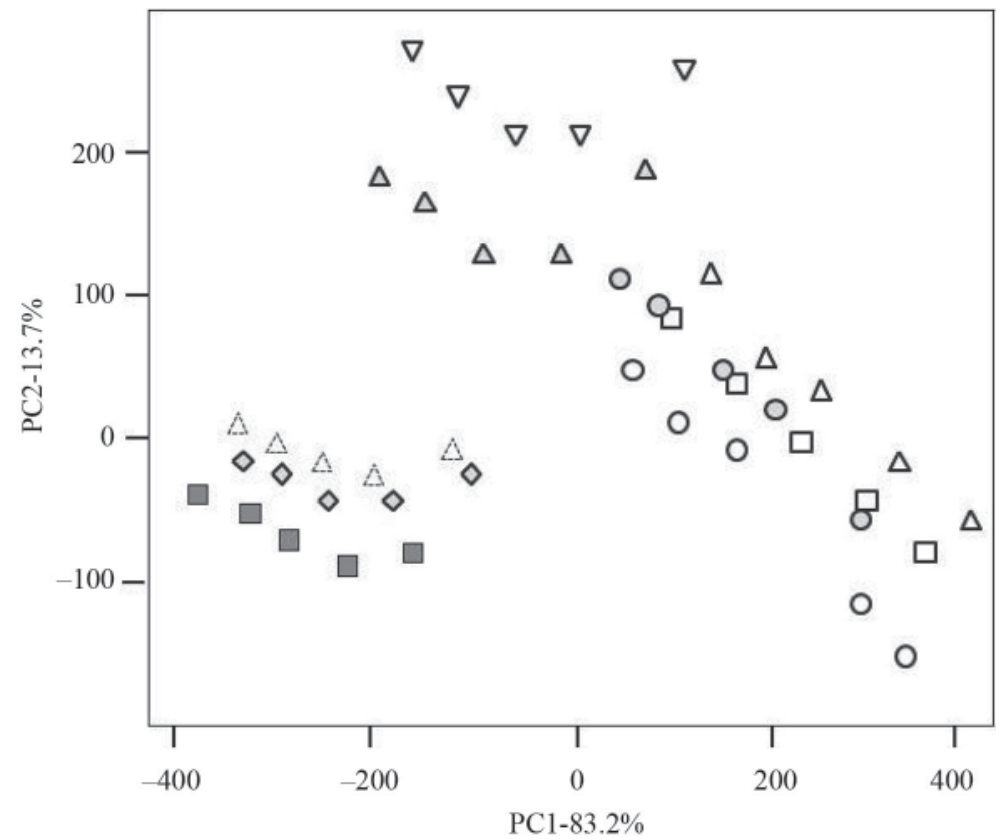

Fig. 1. PCA of the watermelon samples from different Hungarian growing regions (PC1-PC2), results of 2013 $(\triangle: \mathrm{CS} ; \square: \mathrm{CI} ; \mathrm{O}: \mathrm{CL} ; \diamond: \mathrm{JS}, \square: \mathrm{JI} ; \therefore: \mathrm{JL}, \bigcirc: \mathrm{US}, \nabla: \mathrm{UI} ; \triangle \mathrm{UL})$

The samples of different regions were classified correctly. In case of Cece sample groups, Figure 2 shows the LDA plot of the samples. For calibration $100 \%$ and for validation 91.67\% were received, misclassification was not observed.

The interspecific rootstocks are characterized by stronger rooting/vigor, which is an advantage in case of extensive technology, because the water absorption of the plant is more efficient. In 2013 the weather was mostly dry, and in case of Cece, the results (Fig. 1) are in correlation with the root system. This means that the electric sensors identified the samples of interspecific rootstock closer to the ungrafted ones, than the samples form the fruit, witch were grafted on Lagenaria. The rainy summer in 2014 was favonrable for growers without irrigation. The samples could be differentiated by growing areas, and it is assumed that the differences in the enviroment and technology are the reasons for this. 


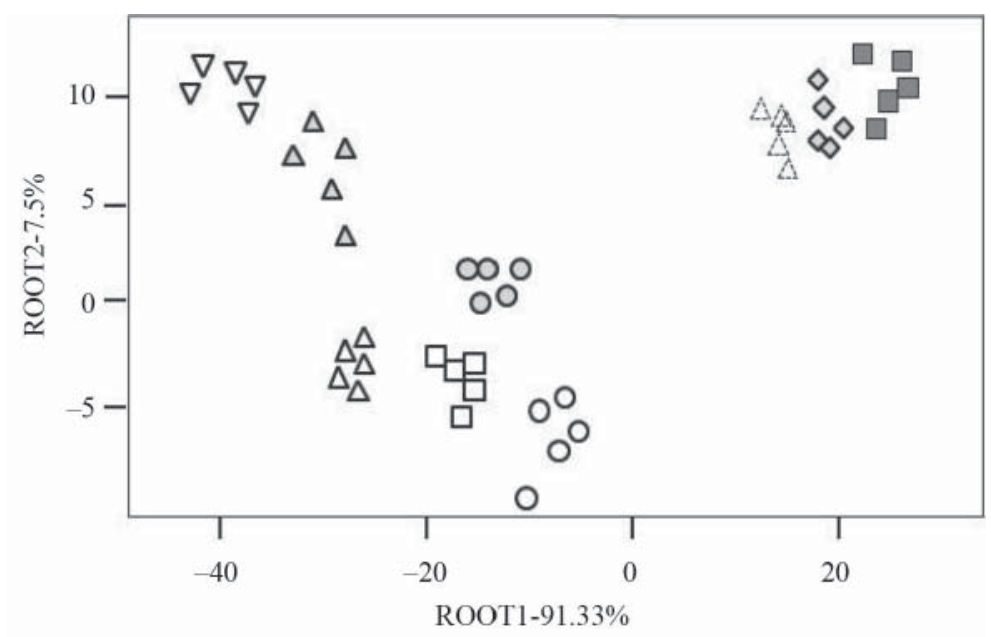

Fig. 2. LDA of the watermelon samples of different Hungarian growing regions (Root1-Root2, calibration: empty dots, validation: filled dots), results of 2013 ( $\triangle:$ CS; $\square:$ CI; O: CL; $\diamond:$ JS, $\square:$ JI; $\therefore:$ JL, $\bigcirc:$ US, $\nabla:$ UI; $\triangle:$ UL)

The electronic tongue analysis selection PCA plot represented a good discrimination of the sample groups based on their origin and treatments in 2014 (Fig. 2). The first two principal components contained more than $97 \%$ of the data variance. There is a clear detachment for Jászszentandrás region from the other samples and from each other; while both Újkígyós and Cece regions seem to be similar in their characteristics. Different treatments (I: interspecific rootstock, l: Lagenaria rootstock, and S: self-rooted) were discriminated as well. In two sites/ regions (Cece, Újkígyós) the interspecific rootstock showed closer results to the ungrafted one (Figs 3,4).

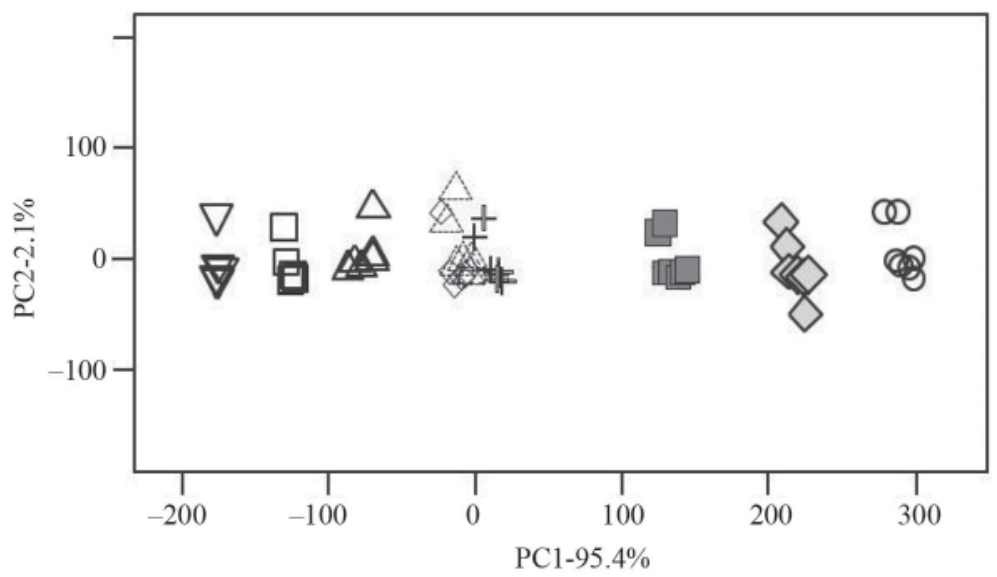

Fig. 3. PCA of the watermelon samples from different Hungarian growing regions (PC1-PC2), results of 2014 ( $\nabla: \mathrm{CS} ; \square: \mathrm{CI} ; \triangle: \mathrm{CL} ; \square: \mathrm{JS} ; \diamond: \mathrm{JI} ; \mathrm{O}: \mathrm{JL} ; \diamond: \mathrm{US} ;+$ : UI; $\therefore .: \mathrm{UL})$ 


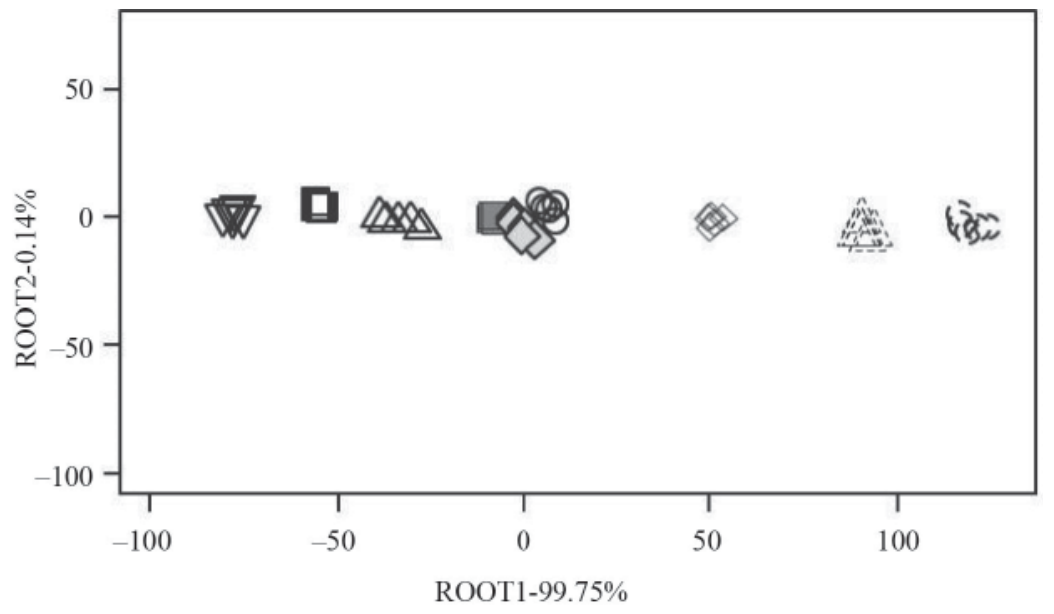

Fig. 4. LDA of the watermelon samples of different Hungarian growing regions (Root1-Root2, calibration: empty dots, validation: filled dots), results of 2014 ( $\nabla: \mathrm{CS} ; \square: \mathrm{CI}, \triangle$ : CL; $\diamond:$ JS; $\therefore:$ JI; $:: \mathrm{JL} ; \square:$ US; $\diamond:$ UI; O: UL)

We concluded that it is possible to use electronic tongue data for distinguishing the origin of watermelon. The results also showed that the difference between the grafted and ungrafted watermelons is less than due to technological and environmental influence. The method can be used for monitoring the effects of the different treatments of watermelon as well.

\subsection{Sensory analysis}

In 2013, a watermelon type breeded for industrial uses was used. In this case, the crispness, mushiness, and red colour are significant, because during post-harvest, it is easier to work with harder material and the flesh may be paler in colour.

No differences were found by tasters/panellists between the samples from Cece in case of venousness and juiciness (Fig. 5). The non-grafted watermelons were a little bit tastier and the sour taste could be felt less. The interspecific treatments from Jászszentandrás got highest score in case of fruit's flesh and venousness. The sweetness and odor intensity were better for the second treatment. In case of the samples from Újkígyós, the highest differences were found in the venousness, mushiness, and juiciness.

In the second year (2014), a different variety of watermelon (Bonta) with larger fruit size was used. This change was necessary, as well-known species are appreciated better by consumers.

The samples from the Lagenaria rootstocks in Cece did not reach the colour intensity of the non-grafted and interspecific plant crops (Fig. 6). In the case of venousness and mushiness, the crops did not show any difference. The intensity of sour taste was stronger in samples from the rootstocks than ungrafted ones. From the second growing area - Jásszentandrás -, the flesh colour of the untreated melons had darker appearance than the treated ones. The score of the sweet taste was higher in case of the Lagenaria, while the score of sour taste was significant at the melons from the interspecific rootstocks. On the third site/region (Újkígyós), the crops from the interspecific plants received the worst judgement with two negative characteristics (venousness and sour taste) from the three available samples. In contrast with this, the crops of the second treatement got favourable scores, also in case of ungrafted plants. 


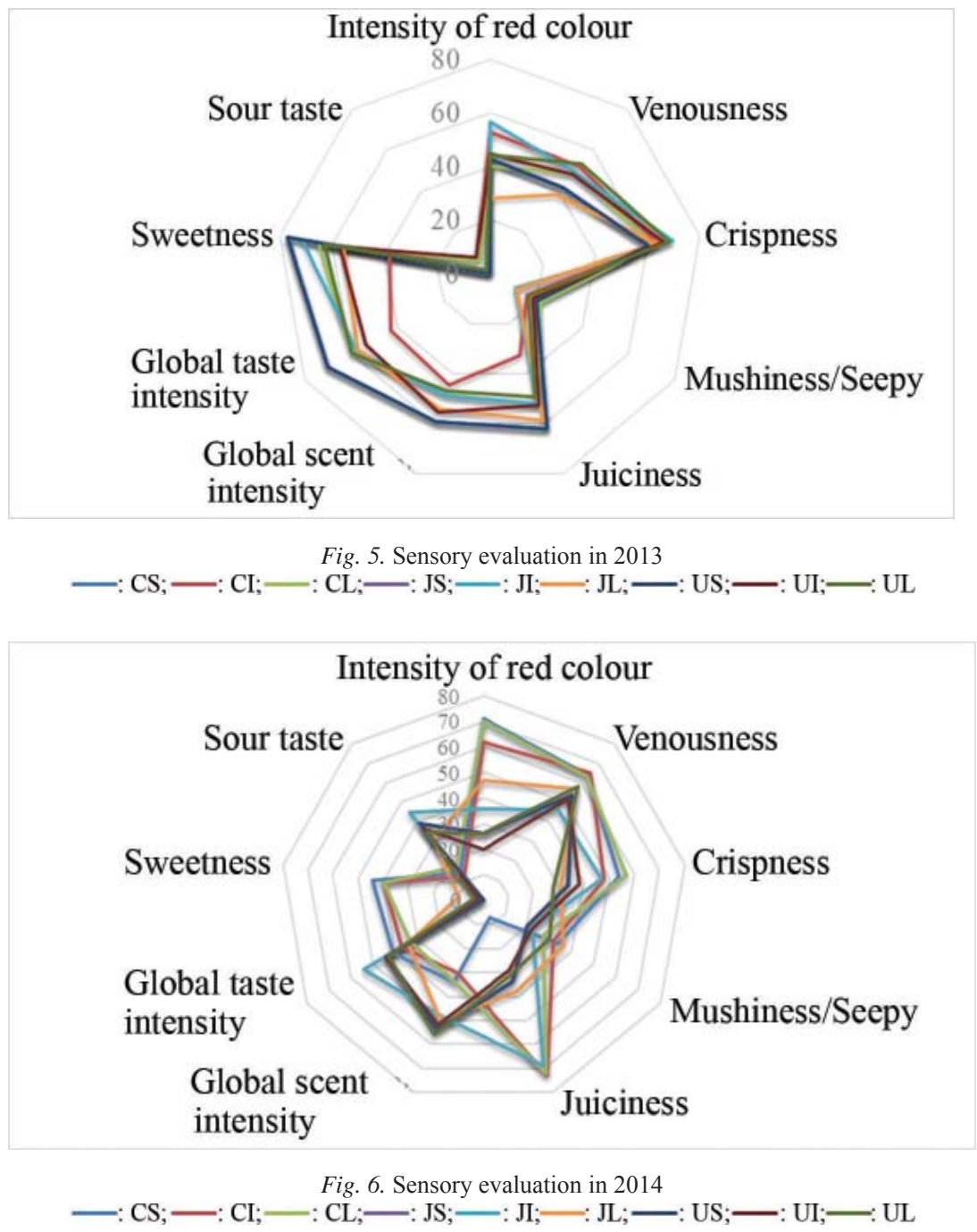

\section{Conclusions}

The results of the study verify that the growing area and the technology are the determinative factors during the cultivation, which influence the qualitative parameters of the watermelon. The three different sites can be seen as three different experiments with similar samples serving the same goals during the same years.

The electronic tongue could clearly differentiate the growing areas in both years, as well as determine the treatment providing the closest fruit to non-grafted watermelon. Electronic tongue provided roughly the differences and similarities, while tasting confirmed the measured values in more details. The sensory evaluation gave a more complex image from the different characteristics of the fruit.

Due to the change of the applied species in the two years: 2013 and 2014 cannot be compared, but the differences between the growing areas and the technology show clearly. 
According to panellists, the interspecific squash rootstock was better than the Lagenaria, independently from variety, both years, in Cece. The samples from the other two research fields showed the opposite result. In their case the Lagenaria rootstock was better.

The evaluation of samples harvested in different years and analysed by several analytical methods has been done using multicriteria optimisation.

As a conclusion, it can be stated that the two types of measurement method can work together well, completing each other in a more detailed, thorough, and practical way. Based on the applied experiment, it is clear that the growing area and the used technology influence the quality of the watermelon fruit not grafting. With intensive growing technology it is possible to reach similar quality by grafting, independently from rootstock type.

This research was supported by the Higher Education Institutional Excellence Program (1783-3/2018/ FEKUTSTRAT) awarded by the Ministry of Human Capacities within the framework of water related researches of Szent István University

\section{References}

Berrueta, L.A., Alonso-Salces, R.M. \& Héberger, K. (2007): Supervised pattern recognition in food analysis. J. Chromatogr. A, 1158(1-2), 196-214.

Bleibaum, R.N., Stone, H., Than, T., Labreche, S., Saint-Martin, E. \& Isz, S. (2002): Comparison of sensory and consumer results with electronic nose and tongue sensors for apple juices. Food Qual. Prefer., 13, 409-422.

Buratti, S., Ballabio, D., Benedetti, S. \& Cosio, M.S. (2007): Prediction of Italian red wine sensorial descriptors from electronic nose, electronic tongue and spectrophotometric measurements by means of Genetic Algorithm regression models. Food Chem., 100, 211-218.

Davis, A.R., Perkins-Veazie, P., Hassell, R., King, S.R. \& Zhang, X. (2008): Grafting effects on vegetable quality. HortScience, 43, 1670-1672.

FALLIK, E. \& ILIĆ, Z. (2014): Grafted vegetables - the influence of rootstock and scion on postharvest quality. Folia Horticulturae, 26(2), 79-90.

Gere, A., Kovács, S., Pásztor-Huszár, K., Kókai, Z. \& Sipos, L. (2014): Comparison of preference mapping methods: A case study of flavoured kefirs. J. Chemometr., 28(4), 293-300.

Gere, A., Sipos, L., Losó, V., Györey, A., Kovács, S., Huzsvai, L., Nabradi, A. \& Kókai, Z. (2015): Applying parallel factor analysis and Tucker-3 methods on sensory and instrumental data to establish preference maps: Case study on sweet corn varieties. J. Sci. Food Agr., 94, 3213-3225.

Gere, A., Sipos, L., KovÁcs, S., KóKai, Z. \& HéBerger, K. (2017): Which just-about-right feature should be changed if evaluations deviate? A case study using sum of ranking differences. Chemometr. Intell. Lab., 161, $130-135$.

ISO (1994): Sensory analysis - Identification and selection of descriptors for establishing a sensoryprofile by a multidimensional approach. International Standard 11035.

ISO (2005): Sensory analysis — Methodology - General guidance. International Standard 6658.

ISO (2007): Sensory analysis - General guidance for the design of test rooms. International Standard 8589.

ISO (2012): Sensory analysis - General guidelines for the selection, training and monitoring of selected and expert assessors. International Standard 8586.

Khakimov, B., Glürdeniz, G. \& Engelsen, S.B. (2015): Trends in the application of chemometrics to foodomics studies. Acta Alimentaria, 44, 4-31.

Losó, V., Gere, A., Györey, A., Kókai, Z. \& Sipos, L. (2012): Comparison of the performance of a trained and an untrained sensory panel on sweetcorn varieties with the panelcheck software. Applied Studies in Agribusiness and Commerce - APSTRACT, 6(1-2), 77-83.

Richards, E., Bessant, C. \& SAINI, S. (2002): Multivariate data analysis in electroanalytical chemistry. Electroanal., 14(22), 1533-1542.

Sipos, L., Kovács, Z., Sági-Kiss, V., Csiki, T., Kókai, Z., Fekete, A. \& Héberger, K. (2012): Discrimination of mineral waters by electronic tongue, sensory evaluation and chemical analysis. Food Chem., 135, 2947-2953.

Sipos, L., Gere, A., Szöllősi, D., Kovács, Z., Kókai, Z. \& Fekete, A. (2013): Sensory evaluation and electronic tongue for sensing flavored mineral water taste attributes. J. Food Sci., 78, S1602-S1608. 